\title{
Criterios Éticos para Psicólogos Jurídicos
}

\section{Ethical Dilemmas for Legal Psychologists}

\author{
Javier Urra Portillo \\ Fiscalía del Tribunal Superior de Justicia y Juzgados de Menores de Madrid
}

\begin{abstract}
Resumen. La ciencia psicológica ha conocido un inusitado desarrollo profesional que concita la demanda de la sociedad en unos profesionales que demuestran por su bagaje teórico y resultados prácticos un alto nivel de formación y una positiva respuesta a las distintas solicitudes. Este calificable como éxito conlleva como en todo crecimiento algunos problemas de acomodación, pues son muchos los ámbitos donde se desempeña el psicólogo y algunos de ellos francamente conflictivos. Añádase que cada vez son más los colegiados profesionales y concluiremos en que en una sociedad donde el cliente cada vez conoce más sus derechos puede existir el riesgo de más denuncias por mala praxis de los profesionales. Por ello, resulta de gran interés saber cómo se desempeñan los profesionales en su práctica diaria y, específicamente, qué temas o situaciones les generan dilemas y, ante ellos, qué respuestas dan.
\end{abstract}

Palabras clave: dilemas, ética, código deontológico, psicología jurídica.

\begin{abstract}
The psychological science has improved an unusual professional development that incites the request of the society to a few professionals who demonstrate, by their theoretical baggage and practical results, a high training level and a positive response to the different demands. This success implies some problems of accomodation, because the areas where the psychologist evolves are many and some of them are very difficult. In addition, every time there are more members in professional colleges. In a society where the client knows his rights, there can exist the risks of more malpractice complaints. It is very interesting to know how the professionals confront their job in the daily practice and specifically what topics will generate dilemmas and what answers to give them.

Key words: dilemmas, ethics, code of ethics, legal psychology.
\end{abstract}

La ciencia psicológica ha conocido un inusitado desarrollo profesional que concita la demanda de la sociedad en unos profesionales que demuestran por su bagaje teórico y resultados prácticos un alto nivel de formación y una positiva respuesta a las distintas solicitudes. Este calificable como éxito conlleva como en todo crecimiento algunos problemas de acomodación, pues son muchos los ámbitos donde se desempeña el psicólogo y algunos de ellos francamente conflictivos. Añádase que cada vez son más los colegiados profesionales y concluiremos en que

La correspondencia sobre esta artículo deberá enviarse al autor al Email: urrainfancia@hotmail.com en una sociedad donde el cliente cada vez conoce más sus derechos puede existir el riesgo de más denuncias por mala praxis de los profesionales. Por ello, resulta de gran interés saber cómo se desempeñan los profesionales en su práctica diaria y, específicamente, qué temas o situaciones les generan dilemas y, ante ellos, qué respuestas dan.

El punto de partida para analizar cuáles son los dilemas éticos de los psicólogos es una preocupante aseveración de Del Río, Borda y Torres, que en 2003 manifestaron que "la información sobre la complacencia respecto a las normas éticas y/o deontológicas de los psicólogos profesionales españoles es inexistente". 
Es fundamental conocer la realidad para actualizar el vigente Código Deontológico y plantear la formación en Ética Profesional tanto en las Facultades de Psicología, como ulteriormente en los cursos de reciclaje organizados por el Colegio de Psicólogos.

Para realizar una revisión teórica de este tema tenemos que remitirnos fundamentalmente a textos anglosajones, pues en nuestro idioma es un ámbito poco desarrollado. Es indispensable abordar temas como el papel del psicólogo forense, la actuación como perito y los procedimientos de familia, que en ocasiones siguen suscitando grandes controversias éticas.

Respecto al psicólogo forense, Urra ha estudiado largamente la práctica profesional y ética del psicólogo que trabaja en la Administración de Justicia, sosteniendo que éste tiene la obligación de conocer en profundidad las características, conceptos y operaciones del sistema jurídico en el que actúa. En su rol profesional está obligado a evitar ofrecer conclusiones sobre las leyes, su interpretación o el sistema legal. Asimismo debe ser cauteloso haciendo predicciones sobre la conducta antisocial; expresar claramente sus recomendaciones o calificaciones, justificando en qué medida están soportadas por el estado actual de la teoría e investigación psicológica; mantener su independencia y autonomía profesional; no prestarse a situaciones confusas; informar al sujeto explorado aunque la solicitud de informe venga realizada por otra persona o institución y no olvidar nunca que el conocimiento de un delito le obliga a denunciarlo. Éste es según Urra el mínimo ético exigible a un psicólogo de este área.

Un aspecto ciertamente polémico es el del informe de parte, que por supuesto cabe y a lugar. Lo que no resulta ético es el contrainforme basado no en el propio estudio y sus consecuentes conclusiones sino en criticar, denostar e invalidar el informe realizado anteriormente por el profesional que lo ha ejecutado.

La práctica profesional o es ética o es una malpraxis, que daña no sólo a quien la sufre y a quien la ejerce, sino al colectivo que ampara al infractor, por lo que estamos legitimados para perseguirle. Para ser un buen profesional hay que identificarse con el rol institucional, si bien no dejándose instrumentalizar (convirtiéndose en brazo ejecutor de la justicia o dando apoyo científico a argumentos parciales del mundo del Derecho). Para alcanzar el aprendizaje éticamente exigible, se ha de posibilitar que los alumnos del último ciclo de la carrera universitaria realicen un verdadero practicum donde ulteriormente podrán laborar (en nuestro caso el Foro).

El comportamiento del psicólogo antes, durante y después del juicio, ha de ser ético y "estético", desarrollando su capacidad empática y erradicando el posicionamiento ante un Número de Expediente al que "no se le pone cara", o la actitud de "mover papel" o la "eficacia aséptica".

Por el contrario se ha de implicar, ser honesto y firmar informes tras reflexionar e indagar para dar respuesta a la exigencia de calidad en cuanto a claridad, precisión, rigor y expresión del grado de fiabilidad, llenando de contenido su labor y siendo asertivo en la defensa de criterios científicos.

Un riesgo inherente a la función es el de "sentirse Dios", irrogándose un poder "en usufructo" que se imparte graciablemente para que un "sujeto" cobre una invalidez, para que se permita a un padre un régimen de visitas, o para que el menor sea internado en tal Centro y por tanto tiempo. Junto a ello existe el peligro de manipular desde nuestro saber, desde nuestra ciencia, utilizando ilegítimamente instrumentos que son traducidos como palabra de ley, pese a que su fiabilidad y validez sea en ocasiones escasa.

El acto de la ratificación, en ocasiones convertido en ziskinización, donde se plantea una estrategia de descrédito del experto, nos responsabiliza de cada afirmación contenida en el informe, nos impele a cuestionarnos los métodos e instrumentos utilizados, interpelándonos sobre el conocimiento de cada caso en particular y nos aleja de los informes "tipo". Como ha dicho algún autor, para ir a ratificarse, habría que prepararse como si uno fuera a ser interrogado por un abogado inteligente, licenciado en psicología y que además, gusta de un lenguaje ininteligible.

Es necesario que el psicólogo se muestre creíble en la ratificación. Para actuar correctamente en esta circunstancia se precisa cualificación y honestidad, su aprendizaje conlleva role-playing, así como asistencia y seguimiento a procesos judiciales completos. La ratificación coadyuva a elevar informes lo 
más objetivos posibles, limitando tanto las inferencias como las predicciones conductuales y evitando plasmar aspectos dudosos y no resueltos, ciñéndonos a conclusiones que se justifiquen en base a conceptos válidos o datos empíricos sólidos.

Del Río nos señala que, dadas las características de la psicología forense, existe riesgo de que los errores tengan graves repercusiones para las personas implicadas en el proceso y para el mismo profesional.

El psicólogo forense se debe a quien le ha contratado dentro del ámbito jurídico-legal, pero también sin duda al evaluado. Dicho cliente, aunque no haya elegido serlo, ha de conocer las obligaciones del profesional y los puntos donde se puedan producir conflictos de intereses. Fundamental será que sepa que los resultados del examen no son confidenciales, podrán y de hecho serán conocidos por los operadores jurídicos; que la exploración no supone un tratamiento y que él no está obligado a responder a las preguntas, si bien y si no lo hace, se reflejará en el dictamen su negativa.

El psicólogo forense en el ámbito penal actúa valorando la responsabilidad criminal, la imputabilidad del procesado, los posibles eximentes, atenuantes, agravantes, también el estrés postraumático de las víctimas y otras secuelas. Cuando se incardina en el derecho civil, su ámbito se refiere a los procesos de tutela, incapacitación de adultos, internamientos psiquiátricos involuntarios, protección de menores, adopción, acogimiento, privación de derechos parentales de progenitores, atribución de custodia en caso de divorcio. Respecto al derecho laboral las secuelas psíquicas de accidentes, el acoso en el trabajo.

Cabe actuar como perito en cuanto a su calidad de experto y a demanda de las instancias judiciales como señala Ávila, pero también como auxiliar e inclusive como asesor, lo que conlleva participar en el antes, durante y después del acto que se celebra en el Foro.

Como experto, aparte de conocer el ámbito psicológico, el psicólogo habrá de manejarse con los requisitos que son propios al ámbito jurídico. Se limitará a prestar sus servicios en aquellos aspectos en los que esté realmente especializado y ha de comprender los derechos civiles de las partes en los procesos legales en los que participe.
El desarrollo profesional como perito puede venir demandado por el juez, el fiscal, los abogados y realizarse de parte o adscrito a las plantillas del Ministerio de Justicia o comunidades autónomas e inclusive de Interior bien por pertenecer a los equipos de la Clínica Médico-Forense, de los Juzgados de Menores, de los Juzgados de Familia, de Instituciones Penitenciarias. La solicitud se hace por escrito y conlleva aceptación y juramento. El psicólogo será citado en forma indicándose día, hora y lugar.

Dadas las características del ámbito forense, se han desarrollado documentos específicos para el trabajo del psicólogo como perito. Entre ellos es espacialmente relevante The European psychologist in forensic work and as expert witness. Recommendations for an ethical practice, elaborado por la EFPA.

Una cosa es que el psicólogo forense haya de contestar a las preguntas formuladas por el juez y otra bien distinta que ha de mantener la confidencialidad con respecto a cualquier información que no influya directamente en los propósitos legales de la evaluación. El psicólogo ha de ser consciente de que su informe va a pasar por muchas manos, por lo que sólo reflejará aquellos datos relevantes para los propósitos de la intervención. Pruebas, cuestionarios y tests deben ser guardados garantizando la seguridad, restringiendo el acceso a los mismos a aquellas personas que por sus características tengan un interés profesional legítimo.

El consentimiento informado ha de prevalecer en todo caso y consignarse la aceptación por parte de quien es explorado y de las terceras personas que el psicólogo entienda como necesarias, si el consentimiento no es dado podrá ser suplido por una orden judicial. Si pese a todo quien ha de ser explorado se niega, el profesional informará al juez.

La mala praxis conlleva consecuencias negativas no sólo para el encausado sino también para el psicólogo y para la colectividad psicológica. Para el psicólogo reviste carácter de delito ya sea porque se considere como falso testimonio o como existencia de ignorancia inexcusable. En cuanto a la colectividad psicológica, como consecuencia de la mala praxis se produce una desconfianza en la conciencia social en el ámbito del derecho, etc. 
La mayor corrupción de un psicólogo forense se da cuando el perito vende corruptamente sus dictámenes, basándose en lo que el abogado desea que digan y no en la verdad. Un potencial factor de parcialidad se adivina cuando el perito condiciona sus honorarios al resultado del juicio.

El perito ha de luchar siempre por su independencia, ahuyentará cualquier presión, buscará adhesión a la honestidad, peleará por la minuciosidad y la objetividad.

La experiencia en los comités de ética nos demuestra que los informes de parte en conflictos matrimoniales son los que conllevan un mayor riesgo de malpraxis. El objetivo del psicólogo ha de ser siempre el mejor interés del niño. Es fácil dejarse influenciar, ser poroso a los comentarios perdiendo la necesaria objetividad e imparcialidad de la evaluación, sesgando la información competente tan necesaria para los tribunales.

En los procesos de separación no se puede actuar con ingenuidad o realizar informes sin las debidas garantías éticas o científicas, pues obviamente cada abogado va a buscar utilizar el contenido bien para aplaudirlo en beneficio de su cliente o bien para denostar al autor de dicho informe si el contenido va en contra de los intereses de su cliente. Resulta muy preocupante el número de denuncias interpuestas contra psicólogos que trabajan en los Juzgados de Familia o que realizan peritajes en este ámbito.

Los informes forenses han de explicitar claramente quien los realiza, quien los solicita, el motivo por el que se realizan y las técnicas de diagnóstico utilizadas. El lenguaje ha de ser claro pero sin sacrificar el contenido técnico. Se ha de dar contestación a las preguntas formuladas aclarando en qué grado científico están sostenidas. Como dijeron Vázquez y Hernández, los informes psicológicos forenses deben seguir una táctica de máxima observación, media descripción y mínima inferencia. Jamás se señalarán características psicológicas de alguien que no haya sido explorado, o bien de la relación con su hijo/a cuando la información sólo es proporcionada por el otro cónyuge (estas malpraxis acontecen con cierta asiduidad, unificando incompetencia e imprudencia).

El psicólogo tendrá prevención respecto a trasmitir información de pacientes sin indicarles que va a ser utilizada para un ámbito distinto del inicial, por ejemplo una terapia de familia. También tendrá sumo cuidado con la información suministrada por los niños, dadas las consecuencias que pudiera tener para su futuro. Obviamente, no se puede valorar a menores de edad sin el consentimiento de los progenitores. Resulta reincidente el que uno de los padres acuda al psicólogo con el niño/a en los días que el régimen de visitas se lo permite sin informar al otro progenitor. Sólo la convicción formal de que es necesario llevar a efecto dicha exploración para modificar una situación grave que pueda estar afectando al normal desarrollo del niño/a puede inducir al psicólogo a seguir adelante con esta "anomalía legal".

Un verdadero problema se genera cuando se confunden los papeles de terapeuta y perito entrándose en una relación dual, pues aún se difumina más la percepción de quién es el cliente. Que un psicólogo clínico comparezca en un juicio para testificar sobre un cliente suyo resulta al menos profundamente problemático, pues el terapeuta tiene y ha de tener un sesgo al introducir la alianza terapéutica con el paciente. Esta alianza ejerce una marcada distorsión sobre la necesaria objetividad del perito.

Resulta necesario discriminar entre obligaciones éticas y legales. De obligado cumplimiento es conocer la ley para, por ejemplo, saber las causas de recusación de los peritos, tales como el parentesco de consanguinidad o de afinidad dentro del cuarto grado con el querellante o con el reo; el interés directo o indirecto en la causa; la amistad íntima o enemistad manifiesta; haber prestado servicios como perito al litigante contrario o ser dependiente o socio del mismo; tener participación en sociedad, establecimiento o empresa que sea parte del proceso.

El perito ha de ser muy cauto y recibir sólo instrucciones de la instancia legítima y no de las partes implicadas en el conflicto. Evitará cualquier tipo de relación dual. Asimismo ha de tener particular cuidado al participar en medios de comunicación para no vulnerar la regla de confidencialidad. Jamás se han de exponer los resultados de las evaluaciones.

Un gran referente mundial en la psicoética, França-Tarragó, indica los distintos supuestos que generan dudas éticas en el actuar profesional del psi- 
cólogo forense. Serían el referido al diagnóstico psicológico, "que el psicólogo plantee sus inferencias respecto al pasado o respecto al futuro, como totalmente ciertas y seguras, implicaría una actitud imprudente o temeraria del profesional"; el de no tener contacto con el implicado y el de la reseña de las limitaciones de la ciencia psicológica y de sus instrumentos diagnósticos.

En cuanto a los procedimientos de familia, son muy interesantes para guiar nuestra práctica profesional algunos documentos como el Protocolo del Colegio Oficial de Psicólogos de Cataluña para peritajes psicológicos en procedimientos de familia, desarrollado por Arch y Jarné. Como este magnífico texto recoge, "el informe pericial psicológico en procedimientos de familia bebe sus principios éticos $y$ deontológicos en el principio de competencia profesional, el mejor interés del menor y realizar el menor daño posible. [ ... ] La realidad de una familia es compleja, a fin de que el/la técnico/a pueda realizar su tarea asegurando al máximo la validez de contenido, es necesario medir y observar un gran número de factores. Así mismo, no es suficiente explorar el funcionamiento individual de cada miembro de la familia, sino que también deben explorarse las pautas de relación de los miembros entre sî".

También es absolutamente recomendable la lectura de la guía de actuación para los psicólogos que trabajan en casos de separación y custodia elaborada por la American Psychological Association: Guidelines for Child Custody Evaluations in Divorce Proceedings. Ofrece pautas básicas a seguir en las evaluaciones y emisión de informes de gran interés y utilidad.

En cuanto a los estudios de Psicología que han tratado de conocer cuáles son aquellas situaciones que plantean dudas éticas a los profesionales en su práctica cotidiana, es imprescindible por su repercusión citar el de Pope, Tabachnick y Keith-Spiegel, realizado en 1987 con muestra estadounidense. Los participantes tenían que valorar 83 conductas que hacían referencia a la evitación de daños, el respeto, el consentimiento informado, la confidencialidad y la competencia entre otros. El cuestionario fue aplicado a 456 miembros de la División de Psicoterapia de la American Psychological Association. Estos autores encontraron que 12 de las 83 conductas fueron difíciles de valorar éticamente por los participantes.

También es relevante citar la investigación de Sullivan, que aplicó el cuestionario de Pope et al a 663 miembros de la Sociedad Australiana de Psicología, concluyendo que algunos participantes encontraron difíciles de juzgar desde el punto de vista ético las situaciones referentes a las relaciones financieras con los clientes.

Urra (2007, tesis doctoral) también ha desarrollado una investigación con un cuestionario amplio, actualizado y acorde a las demandas que le son propias a los profesionales en España, con una muestra mayor y perteneciente a todas las ramas de la Psicología, pues en las investigaciones precedentes la clínica era muy predominante.

Antes de dar paso a la investigación definitiva, Urra realizó un estudio previo con 42 alumnos de $5^{\circ}$ de Psicología del Cardenal Cisneros (Universidad Complutense de Madrid), apreciando una demanda de la asignatura de ética y deontología. Casi todos los alumnos participantes habían tenido el Código Deontológico en sus manos, pero no llegaba a la mitad los que lo habían leído completamente. Se ponía de manifiesto una falta de motivación exterior y de concienciación personal.

En el estudio empírico propiamente dicho, el instrumento utilizado por Urra fue un cuestionario compuesto por 124 dilemas, contestado por 723 psicólogos de todo el país. La muestra utilizada resultó significativa, concretando el margen de error de los datos globales en $\pm 4 \%$.

El objetivo fundamental era conocer qué temas o situaciones generaban dilemas a los profesionales psicólogos e igualmente qué respuestas daban al enfrentarlos. Interesaba saber si ante una misma situación o hecho, las respuestas eran divergentes, dispares, contradictorias o irreconciliables; y si esas diferencias se debían al desconocimiento del Código Deontológico, a la subjetividad de la interpretación del artículo referente, a la inexistencia del mismo o a una redacción equívoca.

El cuestionario fue elaborado con la inestimable colaboración de reconocidos psicólogos, seleccionados según el criterio de ser muy representativos en su área profesional. El listado de dilemas se realizó 
en base al esquema del Código Deontológico en vigor (1987): 13 dilemas hacían referencia a Principios Generales. 6 a Competencia Profesional y relación con otros profesionales. La Intervención, dividida en diferentes áreas se repartía en 14 dilemas de Psicología Clínica y de la Salud. 5 de Psicología Educativa. La Psicología Jurídica fue representada por 9 dilemas. 6 referidos a Psicología del Trabajo, Recursos Humanos y Organizaciones. La Psicología de la Intervención Social se concretó en 5 dilemas. 4 referidos a Psicología del Tráfico y la Seguridad Vial. 5 a Psicología y Drogodependencias. La Psicología Deportiva se reflejó en 4 dilemas y la Psicología Política en otros 4. La investigación y docencia agruparon 9 dilemas. El mayor número de dilemas se refirieron a la Obtención y Uso de la Información, exactamente 21. La Publicidad 7 dilemas. Y los Honorarios y Remuneración 12. Obviamente el cuestionario de dilemas estuvo conformado por los dilemas antedichos pero aleatoriamente entremezclados.

De toda esta investigación, se obtuvieron una serie de apreciaciones acerca de la Psicología Jurídica en relación a los cuestionamientos éticos y deontológicos que se hacían los profesionales de esta área, que luego analizaremos detalladamente.

Los objetivos de la investigación se concretaban en los siguientes: constatar qué situaciones generaban dilemas en la práctica cotidiana de los psicólogos. Apreciar si había coincidencia en las respuestas que daban los colegiados o mucha disparidad ante los mismos dilemas. Ver si la práctica en áreas distintas dentro de la Psicología conllevaba respuestas distintas. Verificar si existían distingos entre quienes llevaban muchos o pocos años ejerciendo la profesión. Auscultar la formación recibida en Ética por los licenciados en Psicología. Comprobar si existían lagunas en el Código Deontológico de 1987, dado el paso del tiempo. Dilucidar si se precisaba corregir algo del articulado de dicho Código Deontológico, por tratarse de una redacción que llevara a equívoco. Aportar al Consejo General de Colegios de Psicólogos los datos y conclusiones para, si se estimaba por su Junta de Gobierno y las comisiones de deontología, incluir aquello que tuviera relevancia en el nuevo Código Deontológico. Mejorar éticamente la práctica profesional de los psicólogos, en aras de optimizar el trato recibido por los clientes y evitación de problemas y sanciones de los compañeros.

En cuanto a las hipótesis generales, el estudio se marcó las siguientes:

1. Hay muchas particularidades que no siendo aceptadas por el Código, sí son admitidas por los colegiados (por ejemplo, que un profesor indique a los alumnos que deben adquirir un libro que dicho profesor ha publicado).

2. Quienes han terminado la carrera más recientemente estarán mejor formados en ética y deontología.

3. Quienes se han encontrado con un dilema, serán más comprensivos con las dudas y aceptación de las dudas y dificultades de quien se encuentre en esa situación.

4. Pese a la defensa individual de la intimidad en temas tan personales y complejos, unido a que un listado cuya contestación exige cuarenta minutos de atención, la respuesta resultaría significativa y superior a las más amplia alcanzada por lo que conocemos en todo el mundo (600 sujetos).

5. Quienes contesten mayoritariamente serán psicólogos sensibilizados con la ética y deontología.

6. Existirán pocos dilemas, pero muy significativos, que reúnan respuestas absolutamente opuestas entre el pensar de unos psicólogos y otros.

7. La mayoría de los psicólogos no han estado en la situación de dilemas que se proponen en el listado.

También se elaboraron dos hipótesis específicas:

1. Existen temas como el de la tortura que concitarán en todos los compañeros la misma repulsa (a trabajar con torturadores). Asimismo todos denunciarán si saben que un niño es víctima de agresiones y maltrato.

2. El ámbito de la Psicología Jurídica y dada la problemática que le es propia, aportará un gran número de contestaciones.

La muestra fue recogida del 1 de junio al 1 de diciembre de 2006. De un total de 723 participantes, el $32.5 \%$ de pertenecían al área clínica, el $22.7 \%$ a Intervención Social y el $22.1 \%$ a Educación. La Psicología Jurídica fue la cuarta rama en participa- 
ción, con un $14.5 \%$ sobre el total de respuestas.

El cuestionario de dilemas contemplaba, como es lógico, todas las áreas de intervención en las que se desarrollan profesionalmente los psicólogos. Los dilemas específicos que hacían referencia a la Psicología Jurídica son los que siguen:

- Entrenar al cliente en "técnicas de credibilidad" antes de declarar en un juicio.

- Hacer una evaluación sobre custodia de menores sin ver a ambos progenitores.

- Recibir al progenitor que, no teniendo la custodia del niño, acude con el mismo en busca de un informe, con desconocimiento por parte del otro progenitor.

- Realizar un contrainforme pericial basado sólo en el informe elaborado con anterioridad por un colega.

- Un consultante solicita una valoración de su personalidad, pues ha sido objeto de un informe "psicopatológico" en el que se dictaminaba su incapacidad para ejercer la patria potestad. Emitir un informe contra el informe del colega si llegamos a la conclusión de que el informe previo no es correcto.

- Realizar un informe para una de las partes y comparecer en el juzgado como testigo de la otra.

- Denunciar a nuestro propio colegio profesional si estimamos que éste no defiende nuestros intereses o los del colectivo en general.
- Hacer un "trueque" con un interno en prisión, diciéndole que si colabora en investigaciones psicológicas se emitirán informes positivos a la Junta de Tratamiento, al entender que la colaboración es un gesto de reinserción y de querer contribuir al desarrollo científico.

- Que el psicólogo de prisiones asuma que tiene más obligación con la institución que con los internos.

El estudio tuvo un diseño transversal, permitiendo obtener información sobre aspectos evaluativos y describir las relaciones existentes entre un conjunto de variables en un momento determinado. Las variables utilizadas como independientes o causativas fueron de selección, al no haberse utilizado manipulación, debido a la utilización de muestras naturales. Se configuró, por tanto, como un diseño univariado - multivariado, con un grupo de medida única.

Uno de los análisis más interesantes fue el de la frecuencia de los dilemas específicos de cada área entre profesionales de dentro y fuera del área. Los resultados concretos del área de Psicología Jurídica fueron éstos:

Como se aprecia en la tabla, los siguientes dilemas no son exclusivos del área de Jurídica: "Recibir al progenitor que, no teniendo la custodia del niño, acude con el mismo en busca de un informe, con desconocimiento por parte del otro progenitor". "Realizar un informe para una de las partes y com-

\section{PSICOLOGÍA JURÍDICA}

\begin{tabular}{|c|c|c|c|c|}
\hline Dilema & $T$ & $p<$ & $\begin{array}{c}\text { Ocurrencia } \\
\text { dentro área } \\
(\%)\end{array}$ & $\begin{array}{c}\text { Ocurrencia } \\
\text { fuera área } \\
(\%)\end{array}$ \\
\hline Entrenar al cliente en "técnicas de credibilidad" antes de declarar en un juicio & -2.469 & .05 & 22.9 & 13.6 \\
\hline Hacer una evaluación sobre custodia de menores sin ver a ambos progenitores & -5.068 & .001 & 47.6 & 24.1 \\
\hline $\begin{array}{l}\text { Recibir al progenitor que, no teniendo la custodia del niño, acude con el mismo en busca } \\
\text { de un informe, con desconocimiento por parte del otro progenitor }\end{array}$ & -.108 & Ns & 24.8 & 24.3 \\
\hline $\begin{array}{l}\text { Realizar un contrainforme pericial basado sólo en el informe elaborado con anterioridad } \\
\text { por un colega }\end{array}$ & -5.969 & .001 & 41.9 & 17.0 \\
\hline $\begin{array}{l}\text { Un consultante solicita una valoración de su personalidad, pues ha sido objeto de un informe } \\
\text { "psicopatológico" en el que se dictaminaba su incapacidad para ejercer la patria potestad. }\end{array}$ & & & & \\
\hline $\begin{array}{l}\text { Emitir un informe contra el informe del colega si llegamos a la conclusión de que el informe } \\
\text { previo no es correcto }\end{array}$ & -7.036 & .001 & 55.2 & 22.2 \\
\hline Realizar un informe para una de las partes y comparecer en el juzgado como testigo de la otra & -1.417 & Ns & 17.1 & 12.1 \\
\hline $\begin{array}{l}\text { Denunciar a nuestro propio colegio profesional si estimamos que éste no defiende nuestros } \\
\text { intereses o los del colectivo en general }\end{array}$ & -1.278 & Ns & 19.0 & 14.2 \\
\hline $\begin{array}{l}\text { Que el psicólogo de prisiones asuma que tiene más obligación con la institución que con los } \\
\text { internos }\end{array}$ & -2.169 & .01 & 18.1 & 9.5 \\
\hline
\end{tabular}


parecer en el juzgado como testigo de la otra”. "Denunciar a nuestro propio colegio profesional si estimamos que éste no defiende nuestros intereses o los del colectivo en general”.

Realizar un informe para una de las partes y comparecer ulteriormente en el Foro está aumentando de manera relevante no sólo en el área de Jurídica sino en otras, pues el psicólogo una vez realizado el informe es llamado a ratificarlo.

Respecto a denunciar a nuestro propio colegio profesional si estimamos que éste no defiende nuestros intereses, va poco a poco aumentando tanto en la Psicología Jurídica que sufre por su función el mayor número de denuncias como en otras áreas por lo inmediatamente arriba indicado cual es la judicialización de los informes.

Interpretamos que la recepción de un progenitor que no teniendo la custodia del niño acude a un despacho profesional de un psicólogo, se da mucho también en la clínica o en el ámbito educativo, dado que no se indica al facultativo para qué se va a utilizar dicho informe. Véase el gráfico que continúa a estas palabras.

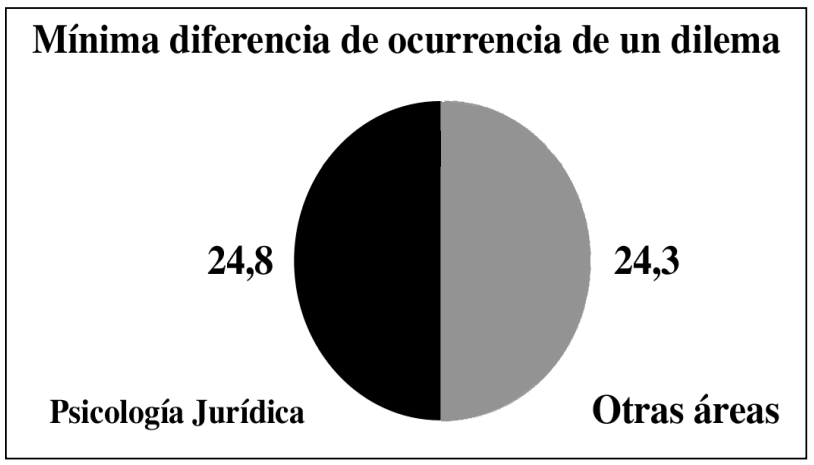

Por contra, acontece mucho más que "Un consultante solicita una valoración de su personalidad, pues ha sido objeto de un informe "psicopatológico" en el que se dictaminaba su incapacidad para ejercer la patria potestad. Emitir un informe contra el informe del colega si llegamos a la conclusión de que el informe previo no es correcto" en el ámbito de la Psicología Jurídica (55.2\%), que fuera de esta área en el 22.2\%. El tema de los contrainformes resulta preocupante en el ámbito de la Psicología Jurídica, véase en el dilema se explicita "emitir un informe contra el informe del colega”.

\section{Máxima diferencia de ocurrencia de un dilema}

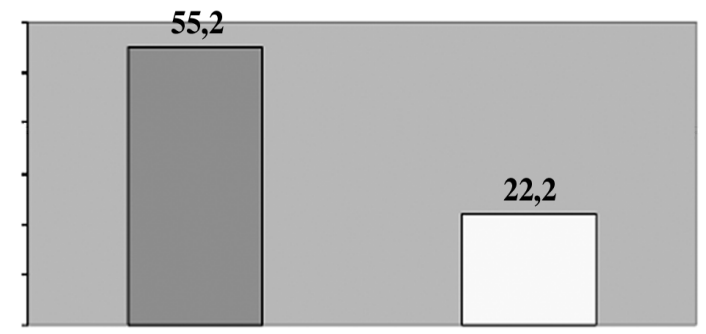

Psicología Jurídica

Otras áreas

Respecto a la frecuencia de ocurrencia de cada dilema, no se apreciaron diferencias por áreas de intervención. Superan el 50\% de frecuencias de ocurrencia: No ofrecer al paciente - si la pide - información detallada de otras alternativas terapéuticas y otros profesionales a los que podría acudir, resulta preocupante pues alcanza el $60.7 \%$. Como resulta grave que el $59.9 \%$ reconozca trabajar cuando se encuentra demasiado estresado para ser efectivo. Un $53.4 \%$ se ha encontrado en la situación de no cobrar a un paciente. Y un $52.1 \%$ en desarrollar un programa para que un niño de 3 años obedezca más a los padres, sin plantearse si responde al mejor interés del niño. Un 50.3\% afirma haber atendido a clientes que presentan problemas anodinos que pueden ser resueltos por ellos mismos y un $50.1 \%$ utilizar revelaciones personales del profesional como técnica terapéutica. De las 124 situaciones que plantea el cuestionario de dilemas, sólo en 6 se supera el 50\% de frecuencias de ocurrencia. Se aprecia en las respuestas: sinceridad, lógica y coherencia. Reseñar el dilema "Utilizar revelaciones personales del profesional como técnica terapéutica" (50.1\%) pues resulta relevante que la mitad de los psicólogos interpreten esta terapia como benéfica, mientras que la otra mitad la valoren como inaceptable. Tampoco es desdeñable (por preocupante) que el $46.7 \%$ haga que los clientes completen los tests (que no son escalas de auto-observación) en su casa, aunque sea puntualmente.

Específicamente en Psicología Jurídica, la máxima ocurrencia dentro del área se da con un $55.2 \%$ en "Un consultante solicita una valoración de su personalidad, pues ha sido objeto de un informe "psicopatológico" en el que se dictaminaba su incapacidad para ejercer la patria potestad. Emitir un informe 
contra el informe del colega si llegamos a la conclusión de que el informe previo no es correcto". La ocurrencia fuera del área, sólo alcanza el 22.2\%. Únase a este dato el más que preocupante, grave 41.9\% de psicólogos jurídicos que reconocen "Realizar un contrainforme pericial basado sólo en el informe elaborado con anterioridad por un colega", algo que sólo realiza el $17 \%$ de los psicólogos no jurídicos. Esta es una de las causas más fundamentadas para recibir denuncias por una mala praxis. La otra causa viene de la mano del $47.6 \%$ de psicólogos jurídicos - frente al $24.1 \%$ de quienes no lo son - que "Hacen una evaluación sobre custodia de menores sin ver a ambos progenitores". Sólo por la obtención de estos datos, merece la pena el esfuerzo colectivo de esta investigación. Todas las alarmas deben encenderse.

Otro análisis muy relevante que aporta luz sobre los problemas éticos a los que se enfrentan los psicólogos en su quehacer profesional es el de los dilemas cuya desviación típica es mayor y que, por ende, indican un alto grado de dispersión en los planteamientos de los psicólogos. "Cobrar a clientes por las citas a las que estos no acuden" es un dilema que genera un gran contraste de pareceres, existe una profunda división y al 50\% entre los que entienden que sí se debe cobrar y los que se oponen a esta práctica, pareciera que el Código Deontológico actual no concrete la postura a tomar o quizás este tipo de decisión debe nacer del propio profesional sin quedar plasmado en norma escrita.

También hay disparidad en utilizar como sujetos experimentales a personas que por su situación sean vulnerables, si bien las respuestas se inclinan a un posicionamiento negativo al respecto.

Un alto grado de desacuerdo concita que un psicólogo abuse del alcohol en lugares públicos y si bien en general se valora como negativo, es de significar que esa disparidad en las respuestas no es achacable al Código Deontológico sino a un posicionamiento personal en la forma de conducirse. Claro que el psicólogo es un ciudadano más, pero no es menos cierto que es un referente para sus pacientes e incluso para la sociedad.

La dificultad en la profesión para homogeneizar criterios ante dilemas que puedan parecer puntuales pero que son indicadores de actitudes y posiciona- mientos, queda reflejado con lo hasta aquí apuntado. Esta disparidad de criterios que genera inseguridad en la ciudadanía se vuelve a apreciar en la polaridad entre los que son favorables y los que no, tanto a proporcionar tratamiento psicológico a un menor en contra de los deseos de sus padres, como a informar a un joven de 18 años de la causa de la muerte de sus padres, siendo esto producto de la violencia de género concluyendo con el suicidio del parricida.

Pueden existir profesionales que no conozcan el Código pero claramente hay otros que, informados del mismo, desoyen su mandato. Se destacan tres ejemplos:

El Código actual vigente señala en su artículo 25 “...en caso de intervención con menores de edad, se hará saber a sus padres o tutores...". Quizás en los veinte años transcurridos desde la publicación en 1987 del Código ha cambiado mucho el concepto de menor, su grado de autonomía, su derecho a la confidencialidad (primordialmente con los denominados "menores maduros") y, por ello, muchos psicólogos dudan en realizar lo que refleja nuestra norma deontológica.

El artículo 27 del referido Código Deontológico explicita: “... se favorecerá al máximo la capacidad de decisión bien informada del cliente para que pueda acudir a otro psicólogo o profesional...". Pareciera que este mandato no se interpreta por los psicólogos como la obligación de informar desde un primer momento de las alternativas existentes.

Artículo 29 "No se prestará a situaciones confusas en las que su papel y función sean equívocos o ambiguos". Esta redacción actual, no parece suficiente, pues que un $39.4 \%$ de psicólogos que se desempeñan en el área de Trabajo indiquen que "sí seleccionarían a profesionales con escasa asertividad" así lo indica.

En el análisis de los dilemas donde los psicólogos muestran una respuesta más homogénea, la inmensa mayoría de los psicólogos están profundamente en desacuerdo con rechazar a un cliente por aversión tras verlo la primera vez, asumen que no pueden dejar llevarse por transferencias o contratransferencias, que los pacientes lo son con sus características y que la vocación y función del psicólogo no permite colgar el cartel de "reservado el derecho de admisión". 
Asimismo, concita una respuesta unitaria y absolutamente contraria el considerar que el secreto profesional cesa cuando la relación psicólogo - cliente concluye.

Un amplísimo acuerdo genera el romper la confidencialidad para informar sobre un abuso infantil. Es un criterio claro de la profesión, tan es así que no se interpreta como dilema.

Existe una clara sensibilidad generando unanimidad contra investigar a una persona que pertenece a un grupo social determinado, ya sea por color, raza, religión, etc., sin su permiso expreso como integrante del grupo además de como individuo.

Coinciden en el acuerdo los psicólogos respecto a que debe contestarse a la autoridad judicial. Se ha entendido lo que significa la autoridad judicial, que puede eximir al psicólogo de silencios exigibles en otros ámbitos.

Manifiesto desacuerdo existe en alterar un diagnóstico para cubrir los criterios de un seguro. Recordemos en este pasaje las dificultades intrínsecas de los colegas norteamericanos, mucho más maniatados por esta realidad que empieza a vislumbrarse en nuestra España.

Los psicólogos de nuestro país muestran su aversión a recomendar que el hijo menor de edad de un paciente con una enfermedad mental grave vea a su progenitor porque se entiende que es un elemento terapéutico positivo para el paciente. Y es que este caso no hace mucho tiempo fue conocido por todos los ciudadanos, transmitido por los medios de comunicación. Un niño hubo de abandonar a la encantadora familia acogedora para volver con su madre biológica afecta de trastorno bipolar de la personalidad, la cual vivía con su marido diagnosticado de esquizofrenia alcohólica. La razón (o sinrazón) de la sentencia fue exactamente que el regreso del menor podría ser positivo para la evolución de la madre. Los psicólogos han sufrido, debatido y se han sensibilizado mucho con este dramático caso en el que un psiquiatra asesoró a un juez, olvidándose ambos del mejor interés del menor y cercenando para siempre el presente y el futuro de un niño.

Una respuesta inequívoca aparece respecto a utilizar tests de personalidad (como el MMPI) para selección de los distintos cuerpos de Policía. Los psicólogos lo tienen claro en el sentido de que un ciudadano al que se le va a dotar de un arma reglamentaria requiere un equilibrio que debe evaluarse con tests, entrevistas, etc. Tan es así, que muchos psicólogos han tenido que contestar a tests psicológicos para ganar su plaza en una oposición, lo que pone de manifiesto que son difícilmente manipulables dichas pruebas, hasta para quien las conoce y maneja.

Denunciar a nuestro propio colegio profesional si se estima que no defiende nuestros intereses o los del colectivo en general, hace confluir una respuesta homogénea desde la posición de acuerdo.

Alivia comprobar que existan temas de total coincidencia entre los psicólogos, criterios inamovibles, convicciones enraizadas, que dan textura y solvencia a nuestro colectivo. Lo deseable es seguir ampliando el consenso.

En la comparación entre quienes se han encontrado en la situación y quienes no, apreciamos que, en general, quienes no han estado expuestos adoptan criterios más rigurosos, considerando menos los matices de la situación. Los que han estado expuestos a una situación encuentran más justificaciones, pues han experimentado los matices que la situación plantea.

Utilizar revelaciones personales del profesional como técnica terapéutica parece a simple vista y para quien no se encuentra en una terapia algo lejano, peligroso y contraproducente. Por el contrario, la experiencia, las horas de terapia, las preguntas del paciente, la indicación personal acorde, el intento de alejar una posición equívoca de quien parece ejecuta un interrogatorio de tercer grado, puede llevar a la aceptación de desvelar aspectos de la vida cotidiana e íntima del propio profesional.

También, el no encontrarse en situación hace que los psicólogos sean más estrictos de manera anticipatoria, sin embargo, la praxis cotidiana, el encontrase trabajando con discapacitados intelectuales, con niños, con presos (poblaciones fácilmente manejables en el sentido de poca mortandad experimental) facilita que el profesional entienda que no se daña, muy al contrario, resulte benéfico para el explorado.

En general sí se aprecian posicionamientos distintos entre aquellos psicólogos que se han encontrado 
en situación de afrontar un dilema y aquellos otros que simplemente lo imaginan y se ponen en situación.

En cuanto a las conclusiones, diremos de manera global que se confirman las hipótesis generales. La respuesta pese al tiempo exigido para contestar al cuestionario y los recelos a desvelar (aún preservado el anonimato) temas íntimos, fue muy buena y los participantes mostraron una gran sensibilidad en las múltiples observaciones escritas a pie de cuestionario. Se confirmó que la mayoría de los psicólogos no habían estado en la situación de dilemas que se proponían en el listado y que quienes se habían encontrado con un dilema eran más comprensivos con las dudas y aceptación de las dificultades de quien se ve implicado en esa situación.

Existían pocos dilemas muy significativos que reunían respuestas absolutamente opuestas de unos psicólogos y otros. Igualmente existían particularidades que no siendo aceptadas por el Código sí lo eran por la práctica cotidiana de los profesionales (si bien puntuales).

No se ratificó por el contrario la hipótesis de que quienes habían terminado la carrera más recientemente estaban mejor formados en deontología y ello porque sigue - en general - sin enseñarse a los alumnos el contenido de la ética y deontología profesional y, aún menos, enfrentarse a resolución de conflictos.

Las hipótesis específicas se confirmaron, tanto en que el ámbito de la Psicología Jurídica por la problemática de denuncias que le es propia participaría de forma hipertrofiada (si bien dejando traslucir algunas conductas contrarias a nuestras normas deontológicas), como en que para satisfacción y tranquilidad de todos existen temas que concitan un acuerdo unánime, es el caso de la repulsa a trabajar con torturadores o la asunción del deber de denunciar sabedores de que un niño es víctima de agresiones y maltrato.

\section{Referencias}

Del Río, C. Borda, M. y Torres, I. (2003). Valoración ética de algunas prácticas de los terapeu- tas por estudiantes de Psicología. En Psicología Conductual, 11, 261-281. Universidad de Sevilla.

Urra, J. (1994). La ética del psicólogo en la Administración de Justicia. Anuario de Psicología Jurídica, 4, 43-51. Madrid: Colegio Oficial de Psicólogos.

Urra, J. (1994). Psicología Forense. El compromiso ético. Actas del Congreso de Psicólogos del Sur de Europa. Marsella.

Urra, J. (2002). La ética en los distintos momentos del procedimiento judicial, incluida la ziskinización, en Urra, J. (ed.). Tratado de Psicología Forense (pp. 611-621). Madrid: Siglo XXI.

Urra, J. (2007) Tesis doctoral: Psicología y Deontología. Estudio empírico basado en dilemas éticos. Universidad de A Coruña.

Del Río (2002). Monográfico sobre Ética Profesional y Psicología. Revista de Psicología Universitas Tarraconensis, 24, 1-2. Publicado en Infocop. Suplemento Informativo de Papeles del Psicólogo. 86. Diciembre, 2003.

Ávila, A. (1986). El peritaje psicológico en los procesos judiciales. En F. Jiménez-Burillo y M. Clemente (Comps.), Psicología social y sistema penal, 185-207. Madrid: Alianza Editorial.

Federación Europea de Asociaciones de Psicólogos, EFPA, (2001). El Psicólogo Europeo en el Trabajo Forense y como Perito. En Colegio Oficial de Psicólogos de España - COPE, 2004, Ética y Deontología para Psicólogos. Madrid: Autor.

Vázquez, B. y Hernández, J.A. (1993). El rol del psicólogo en las clínicas médico-forenses. En J. Urra, y B. Vázquez (eds.), Manual de Psicología Forense (pp. 177-204). Madrid: Siglo XXI.

França-Tarragó, O. (2001, p. 112, $3^{\text {a }}$ ed). Ética para psicólogos. Bilbao: Desclée de Brouwer.

Arch, M. y Jarne, A. (2002). Protocolo del COPC para peritajes psicológicos en procedimientos de familia. Génesis y fundamentación teórica de la propuesta del protocolo del COPC. Full Informatiu del Col.legi. Oficial de Psicolegs de Catalunya, 152, 4-5.

American Psychological Association (1994). Guidelines for Child Custody Evaluations in 
Divorce Proceedings. American Psychologist. 49, 677-680. Washington, D. C.: American Psychological Association.

Pope, K.S. Tabachnick, B.G. y Keith-Spiegel, P. (1987). Ethics of Practice: The belief and behaviors of psychologists as therapist. American Psychologist, 42, 993-1006.

Sullivan, K. (2002). Ethical beliefs and behaviours among Australian psychologists. Australian Psychologist, 37, 135-141.

Artículo recibido: 05/04/10

Revisión recibida: 22/04/10

Artículo aceptado: 26/04/10 